\title{
Detection and identification of green vitriol in autopsy material- A case study
}

\author{
Vinod Dhingra ${ }^{1, *}$, Jyotsna Pandey ${ }^{2}$ \\ Senior Scientific Officer, Forensic Sciences Laboratory, Sagar, Madhya Pradesh, India \\ *Corresponding Author: \\ Email: vdhingraso@hotmail.com
}

\begin{abstract}
Death due to ferrous sulphate is uncommon in literature. On ingestion, initially there is a relative lack of severe symptoms and signs. Hence, there is usually some delay before the affected person needs medical care. Ferrous sulphate is however toxic and death occurs due to multi-organ failure in substantial ingestions. The diagnosis of ferrous sulphate poisoning depends mainly on the history, and clinical and postmortem findings. Chemical analysis utilizing conventional equipment may not be helpful. The proper physical evidences collected from scene of crime may sometime be helpful. A case reported in which twenty eight-yearold lady consumed a small amount of green sauce made up of mint (pudina) offered by her husband in which he intentionally added ferrous sulphate to get rid from him. A short time thereafter she suffered from diarrhea and vomiting, for which symptomatic treatment was given by a physician from a local hospital. But the condition of the lady worsened and she died on the same day after ingestion of the poison. In the present study post mortem findings and analysis of green vitriol in autopsy material and physical evidences discussed.
\end{abstract}

Keywords: Ferrous sulfate poisoning, Green vitriol.

\section{Introduction}

Iron compounds generally found in +2 and +3 valence forms, the compound in which iron remains in +2 forms usually have a green colour. Acute poisoning is likely to occur through the oral route, whereas chronic poisoning may occur mainly through small oral doses or absorption by skin. Death due to poisoning with ferrous sulphate is uncommon in literature. The applicability of ferrous sulphate in several works makes its availability in the market easier, which increase the incidence of suicidal, homicidal and accidental exposures. The problem with ferrous sulphate poisoning is that in the initial stages there are no major manifestations, and therefore the patient may delay seeking medical attention until it is too late. If such cases are not treated properly from the beginning all major organs get affected seriously which leads to multi-organ failure. ${ }^{1,3}$ In the present study post mortem findings and analysis of green vitriol in autopsy material and physical evidences discussed.

\section{Case History}

A twenty eight-year-old lady consumed a small amount of green sauce made up of mint (pudina) offered by her husband in which he intentionally added ferrous sulphate to get rid from him. A short time thereafter she suffered from diarrhea and vomiting, for which symptomatic treatment was given by a local physician from the city hospital. However, on the same day following exposure, the lady developed anuria for which he was admitted at a major private city hospital. Renal failure was diagnosed and peritoneal dialysis was performed. But the condition of the lady deteriorated and she died on the same day after ingestion of the poison.
Postmortem Findings: On postmortem examination the entire body appeared edematous externally. Internal examination revealed the brain to be congested with mild edema. The esophagus showed corrosion. Pleural cavities contained bloodstained fluid. Both lungs were congested and edematous. Petechial hemorrhages were also present on the epicardial surface of the heart. Liver appeared fatty and yellowish. Kidneys were enlarged and pale with red lines in the small cortex. Stomach contained greenish viscous fluid without any unusual smell. The mucosas were largely congested.

Experimental: Ferrous sulphate, Nitric acid, Potassium ferrocyanide, Sodium rhodizonate and Barium chloride used were AR grade. Doubly distilled water was used throughout the study.

Test for Ferrous Sulphate ${ }^{4,7}$

Test for Iron: Take some drops of test solution or original solution, add to it a drop of conc. Nitric acid and boiled for few minutes, after that Potassium ferrocyanide solution added. Development of blue color indicates for the presence of Iron.

\section{Test for Sulphate:}

1. In an appropriate portion of the test solution along with double distilled water in a beaker added, shook well and filtered it, now few $\mathrm{ml}$. of this filtrate in a test tube, few drops of dilute hydrochloric acid followed by $0.25 \mathrm{M}$ barium chloride solution added. White precipitate, which is insoluble in water and acid, indicates the presence of sulphate.

2. A drop of barium chloride solution $(0.25 \mathrm{M}-61.1 \mathrm{~g}$ barium chloride dihydrate diluted in 1 litre of water) on a filter paper and add a drop of fresh solution of sodium rhodizonate (5\%). Reddish brown colour spot appears. Now add a drop of acid or alkaline test solution. Disappearance of colour 
spot indicates the positive test for the presence of Sulphate.

\section{Discussion}

Ferrous sulphate is seldom encountered chemical in clinical and forensic toxicology. It is a green crystalline solid, and is commonly used as a pigment. In undiluted form, ferrous sulphate acts as a systemic poison. Oral intake is reported to cause intense gastrointestinal irritation or ulceration and corrosion, epigastric pain, nausea, vomiting, diarrhea, vertigo, fever, muscle cramps, hemorrhagic diathesis, multi organ failure, acute multisystem shock, coma, and even death, depending on the dose. Prominent iron deposition in gastric and small intestinal mucosa was associated with necrosis, with some cases demonstrating prominent vascular iron deposition. These observations were correlated with increased levels of iron in various tissues, as determined by analytical atomic absorption spectrophotometry. The morphologic and chemical analysis data provide information on the pathogenesis of ferrous sulfate poisoning; the vascular iron deposition may be related to subsequent hemorrhage. In the liver the periportal necrosis is probably a direct cytopathic effect of the highest levels of iron carried to these cells by the portal blood flow. In this particular case, there is evidence of initial gastrointestinal irritation in the form of vomiting and diarrhea, but subsequently, the manifestations were mainly renal in nature.

\section{Conclusion}

Availability of ferrous sulphate is likely to get progressively easier in India due to various uses of this compound; therefore the incidence of ferrous sulphate poisoning is expected to rise in the future. In the case being reported, there was a time lag in beginning proper treatment because the attending doctors were not aware about the exact toxic profile of the ferrous sulphate chemical. Selected viscera including stomach, liver, and kidneys, and blood were tested for routine chemical analysis. But no pesticide or drugs were detected on elaborated study we found the positive tests for Ferrous and Sulphate ions. It is imperative to create awareness of medical professionals about the toxicity of sulphates in general and ferrous sulphate in particular so that fatalities can be reduced. This is all the more important when one considers the fact that diagnosis of ferrous sulphate poisoning depends mainly on the history and clinical and postmortem findings. Chemical analysis is usually not helpful until proper physical evidences are confiscated from scene of crime. As happened in this case where investigating officer seized a silpatta (stone) [Fig.1] used for preparation of mint (pudina) sauce contains some trace of green coloured substance on it which was identified as ferrous sulphate [Fig. 2.]

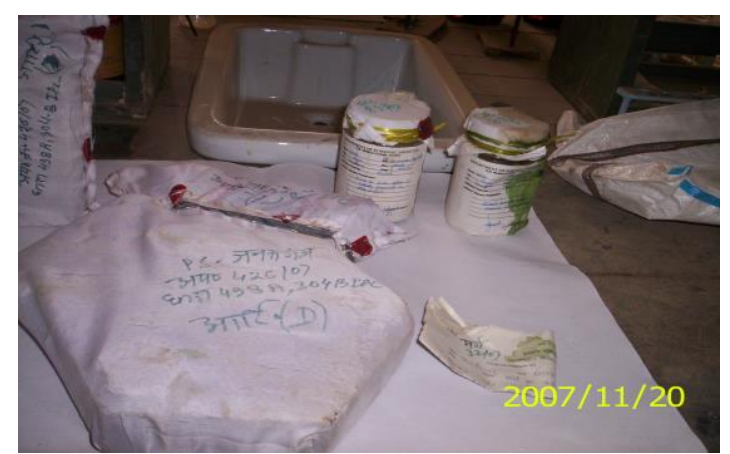

Fig. 1: The case exhibits confiscated from scene of crime and during postmortem

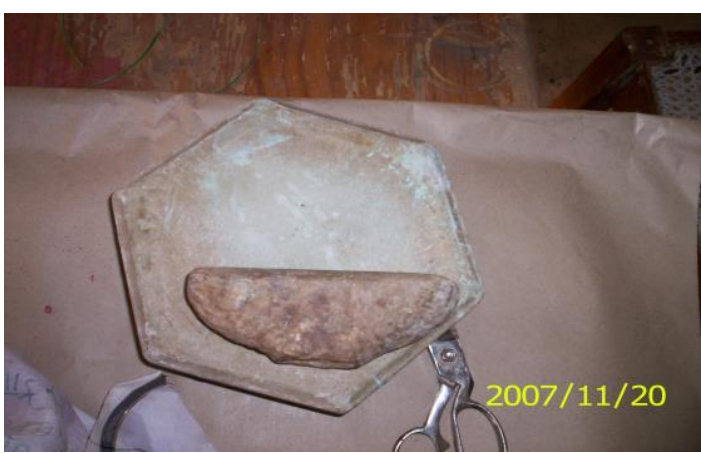

Fig 2: The silpatta (Stone) used for preparation of mint sauce having traces of $\mathrm{FeSO}_{4}$

\section{References}

1. Stift A, Friedl J, Laengle F., N Eng J Med 1998;338:766767.

2. Hay E, Derazon H, Eisenberg Y, Natalia B., J Emerg Med. 2000;19(2):159-163.

3. Clayton GD, Clayton FE. Patty's Industrial Hygiene and Toxicology, Vol. 2C, Toxicology, 4th ed., John Wiley \& Sons, New York, NY, 1994.

4. Analytical Chemistry by S. Shapiro \& Ya. Gurvich, MIR Publishers, Moscow, 1972.

5. Spot test in inorganic analysis by Fritz Feigl, sixth edition, Elsevier Publishing Company, Netherlands, 1982.

6. A textbook of Quantitative Inorganic Analysis by Vogel. 5th edition, 2004.

7. Arthur I. Vogel, A Text Book of Macro and semi micro Qualitative Inorganic Analysis, 4th edition, 1974. 